\title{
Cost-Effectiveness of Lactobacillus Rhamnosus GG Associated with Oral Rehydration Therapy Compared with Oral Rehydration Therapy Alone on the Treatment of Children with Acute Diarrhea in Mexico
}

\author{
Hector Daniel Cueto Romero ${ }^{*}$, Renata Nahuys Tebyriçá Prioli ${ }^{2}$, Diego Kashiura ${ }^{3}$, Elene Nardi ${ }^{3}$, \\ Teresa Lemmer $^{3}$ \\ ${ }^{1}$ Corporativo Procter \& Gamble, Calle Retorno 7 \#1, Col Conjunto Urbano Green House, 52787, \\ Municipio Huixquilucan, México \\ ${ }^{2}$ Procter\&Gamble Industrial e Comercial LTDA, Av. Doutor Chucri Zaidan, 296, $24^{\circ}$ a $27^{\circ}$ andares e \\ Mezanino, conjuntos 241 a 271, Vila Cordeiro, São Paulo - SP, 04583-110, Brazil \\ ${ }^{3}$ Kantar, Health Division, Av. Francisco Matarazzo, 1350, 5th floor, 05001-100, São Paulo, Brazil
}

Received Date: September 26, 2019; Accepted Date: October 02, 2019; Published Date: October 11, 2019

"Corresponding author: Hector Daniel Cueto Romero, Corporativo Procter \& Gamble Calle Retorno 7 \#1, Col Conjunto Urbano Green House, 52787, Municipio Huixquilucan - México; Email: cueto.dh@ @g.com

\section{Abstract}

Subject: This study aims to evaluate the cost-effectiveness of Lactobacillus Rhamnosus GG (LGG) associated with oral rehydration therapy (ORT), compared with ORT alone, on the treatment of children with acute diarrhea in Mexico, from patient's perspective. Using published data on probiotics and costs, a cost-effectiveness model was built using time horizon of 15 days and cycle length of one day. Four health states were considered: 1) acute diarrhea (inpatient cases); 2) acute diarrhea (outpatient cases); 3) healed; 4) death. The base case was modeled as a hypothetical cohort of children from 1 month to 48 months of age diagnosed with acute diarrhea. A Mexican patient's perspective was adopted. Outcome included was days of diarrhea avoided. Deterministic sensitivity analyses were conducted. The ICERs less than $\$ 459,058.95$ per day of diarrhea avoided were considered cost effective. Deterministic sensitivity analysis was performed to measure the robustness of the model. Analysis showed that days with diarrhea avoided of patients in LGG and ORT was 12.60 days and for those only in ORT was 11.41 days. The total costs related to both groups were MXN 1,356.39 (LGG + ORT) and MXN 1,818.21 (ORT). Probiotic use dominated (more effective and less costly) no probiotic use in all cases in deterministic sensitivity analysis.
Conclusion: LGG + ORT for acute diarrhea in children from 1 month to 48 months of age in Mexico more effective and less costly than only ORT. The use of this probiotic could lead to substantial cost savings.

Keywords: Acute diarrhea; CEA; $L G G$; Pediatric

\section{Introduction}

Acute diarrhea a common health issue worldwide, it is usually caused by an inflammation of the gastrointestinal tract. This inflammation is related to several viral, parasites or bacterial agents and, in children, rotavirus is the most common pathogen [1]. The World Health Organization (WHO) estimates that there are approximately 1.7 billion cases of childhood diarrheal disease per year. Globally, it is the second leading cause of death in children $<5$ years-old (around 525,000 deaths annually) and leading cause of malnutrition [2-4]. In Mexico, the prevalence of acute diarrhea episodes decreased from $12.6 \%$ in 2000 to $11.0 \%$ in 2012. In 2012, most cases were registered in rural areas and in children < 1-year-old. The states with higher rates were Tabasco, Yucatán, Guerrero and Baja California Sur [5].

The manifestation consists in the sudden occurrence of more than three watery or loose stools per day. The most 
incident population is children under 5 years of age, especially neonates, and the duration varies from 7 to 14 days, approximately [6-8]. Dehydration and negative nutritive balance are the main consequences of acute diarrhea cases. Hence, treatment focuses on the reestablishment of body fluids levels and adequate diet [68].

The acute diarrhea management includes different strategies that can include rehydration therapy, supplemental zinc therapy, multivitamins and minerals, diet and use of probiotics [9-11].The active treatment with probiotics is recommended for children with acute gastroenteritis in adjunct to oral rehydration therapy (ORT) to reduce duration and intensity of symptoms. In European Society for Pediatric Gastroenterology, Hepatology, and Nutrition (ESPGHAN) \& European Society for Infectious Diseases (ESID) Guideline, it was established a strong recommendation on the use of $L$. Rhamnosus $G G$ and $S$. Boulardii, regardless of the evidence quality [11].

The efficacy and safety of Lactobacillus Rhamnosus GG associated with ORS to treat acute diarrhea in infants was assessed by several randomized-clinical trials (RCT). In a systematic review and meta-analysis developed by the Cochrane Collaboration, the use of probiotics reduced the duration of diarrhea in mean 24.76 hours. It also decreased the risk of diarrhea lasting 4 days or more and the stool frequency on day 2 [12]. In other evaluation, the use of $L$. Rhamnosus $G G$ was related to the reduction in the duration on the length of diarrhea was in mean and the duration of hospitalization was lower [13, 14].

There is not, however, economic evaluations of Lactobacillus Rhamnosus $G G$ in the treatment of acute diarrhea episodes in children. Therefore, this study aim is to evaluate the costeffectiveness of Lactobacillus Rhamnosus $G G$ (LGG) associated with oral rehydration therapy (ORT), compared with ORT alone, on the treatment of children with acute diarrhea in Mexico, from patient's perspective.

\section{Methods}

\section{Model Description}

A Markov Model was developed to simulate the clinical course of a patient from 1 month to 48 months of age diagnosed with acute diarrhea. The Cost-effectiveness model was built using Microsoft Excel and designed to evaluate changes in four health states: 1) acute diarrhea (inpatient cases); 2) acute diarrhea (outpatient cases); 3) healed; 4) death. Time horizon was 15 days and cycle length was defined as one day.

\section{Patients and Economic-Effectiveness Outcomes}

It was considered a patient from 1 month to 48 months of age diagnosed with acute diarrhea and a Mexican patient's perspective was adopted.

Data were based on a systematic literature review and metaanalysis, conducted by Szajewska, et al., which evaluated efficacy and safety of LGG in the treatment of children with acute diarrhea $[15,16]$. A total of 15 randomized-controlled trials (RCT) were included and pooled data from 11 RCTs demonstrated that the use of LGG was associated with a mean reduction of duration of diarrhea in 1,05 days. Transition probabilities were extracted from this meta-analysis [16]. Per day, the risk of having diarrhea was statistically significant lower on days two, three, and after day seven (Table 1) (Figure 1).To capture the global clinical effect of the intervention and comparator, the measure of effectiveness adopted was avoided days of diarrhea.

The model assumed that in this time horizon there is no mortality and in one day patients can switch-over from outpatients to in patients, but not vice versa. The $10 \%$ probability of been hospitalized was obtained of an interview with a Mexican physician, which have considered a private perspective. The transition probability of was calculated using the following equations [17]:

$$
\begin{gathered}
r=-\frac{1}{t} \ln (1-p) \ldots \ldots \ldots \ldots(\text { Eq. } 1) \\
r: \text { event constant rate } \\
t: \text { unit time }
\end{gathered}
$$

$p$ : probability that an event will occur during time $t$

$$
\begin{gathered}
p=1-e^{-r t} \ldots \ldots \ldots \ldots(\mathrm{E} \\
r: \text { event constant rate } \\
t: \text { unit time }
\end{gathered}
$$

$p$ : probability that an event will occur during time $t$ 
Cost-Effectiveness of Lactobacillus Rhamnosus GG Associated with Oral Rehydration Therapy Compared with Oral Rehydration Therapy Alone on the Treatment of Children with Acute Diarrhea in Mexico
Copyright: (C)

2020 Hector Daniel Cueto Romero*

\begin{tabular}{|c|c|c|c|}
\hline \multirow{2}{*}{ Day } & \multicolumn{2}{|c|}{ Risk of having diarrhea } & \multirow{2}{*}{ Source } \\
\cline { 2 - 4 } & LGG + ORT & ORT & Szajewska, et al. $(2013)$ \\
\hline 2 & $26 \%$ & $71 \%$ & Szajewska, et al. $(2013)$ \\
\hline 3 & $26 \%$ & $23 \%$ & Szajewska, et al. $(2013)$ \\
\hline 4 & $24 \%$ & $18 \%$ & Szajewska, et al. $(2013)$ \\
\hline 5 & $21 \%$ & $18 \%$ & Assumption \\
\hline 6 & $21 \%$ & $10 \%$ & Szajewska, et al. $(2013)$ \\
\hline After day 7 & $3 \%$ & $10 \%$ & Szajewska, et al. $(2013)$ \\
\hline After day 10 & $2 \%$ & \\
\hline
\end{tabular}

Table 1. Transition Probabilities.

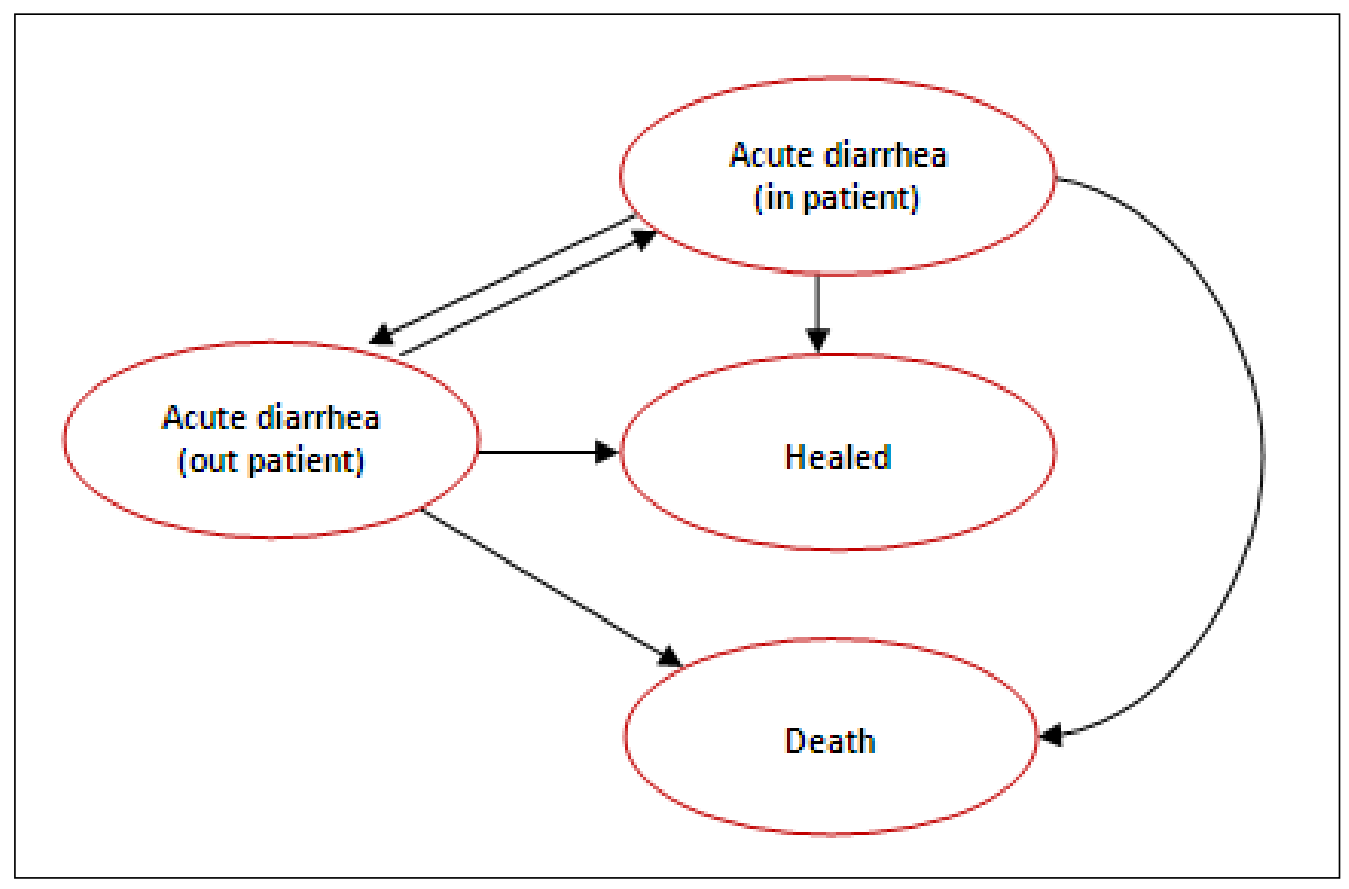

Figure 1: Markov Model.

\section{Resource Use and Costs}

The treatment of LGG was defined as two daily doses of 1010 colony forming units (CFU) for four days, even if diarrhea was discontinued earlier. ORT was defined as a daily dose of $100 \mathrm{~mL} / \mathrm{kg}$ of oral rehydration solution containing sodium chlorate, potassium citrate, sodium citrate, glucose and zinc. The base case considered a patient with $10 \mathrm{~kg}$ of body weight.

LGG and ORT costs were extracted from by price. The median price ( 7 pharmacies) of the presentation with 8 sachets of LGG was MXN 231.00 (216.00 - 272.89). For ORT $500 \mathrm{~mL}$, the median price (14 pharmacies) was MXN 19.75 (18.9024.02). All published prices were considered, and the median prices were used on the base case.
Direct medical costs were included. For both in-patients and outpatient's data were obtained from an economic model to estimate costs outcomes of rotavirus gastroenteritis in eight Latin American and Caribbean countries, including Mexico. Direct medical costs included the costs of tests, medication, supplies, facilities, and personnel needed for treatment [18]. For outpatient patient, it was considered per visit cost, diagnostics and medication as medical resources. The costs were converted of 2003 US dollars to 2003 Mexican Pesos and inflation rate Mexico historical was used to adjust to 2018 Mexican Pesos $[19,20]$.

\section{Analysis Overview}

The outcome was the risk of having diarrhea per day until 15 days. We calculated the difference in cost per patient using two sachets per day of LGG plusORT versus ORT and 
Cost-Effectiveness of Lactobacillus Rhamnosus GG Associated with Oral Rehydration Therapy Compared with Oral Rehydration Therapy Alone on the Treatment of Children with Acute Diarrhea in Mexico
Copyright: $($ )

2020 Hector Daniel Cueto Romero* considered the transition probability of 0.007 of been hospitalized for both groups. Costs of in- and out-patient was multiplied by proportion obtained from transition probability of 0.007 .

\section{Sensitivity Analyses}

A deterministic sensitivity analysis was performed to measure the robustness of the model. It was included for all inputs in the model, considering different upper and lower values and the results were reported graphically in a tornado plot to reveal which factors have the greatest effect on base case variability.

\section{Results}

Analysis over a life cycle of 15 days showed that days with diarrhea avoided of patients in LGG and ORT was 12.60 days and for those only in ORT was 11.41 days. The total costs related to both groups were MXN 1,356.39 (LGG + ORT) and MXN 1,818.21 (ORT) (Table 2).

The incremental cost-effectiveness ratio (ICER) was MXN 389.96 per day of diarrhea avoided. As show in (Figure 2), the sensitivity analysis showed that the costs of outpatient and the numbers of sachets per day of LGG was the most influential parameters followed by risk of diarrhea (Figure 2). At all cases, probiotics remained the preferred strategy, with a negative ICER.

\begin{tabular}{|c|c|c|c|}
\hline Parameter & Vivera ${ }^{\circledR}$ (LGG) & Standard of care & \multicolumn{2}{c|}{ Incremental } \\
\hline Costs & MXN 1,356.39 & MXN 1,818.21 & -MXN 461.82 \\
\hline Days of diarrhea avoided & 12.60 & 11.41 & 1.18 \\
\hline \multicolumn{2}{|r|}{ Incremental cost-effectiveness ratio (ICER) } & -MXN 389.96 \\
\hline
\end{tabular}

Table 2: Days with diarrhea avoided of patients in LGG and ORT and costs related to treatment.

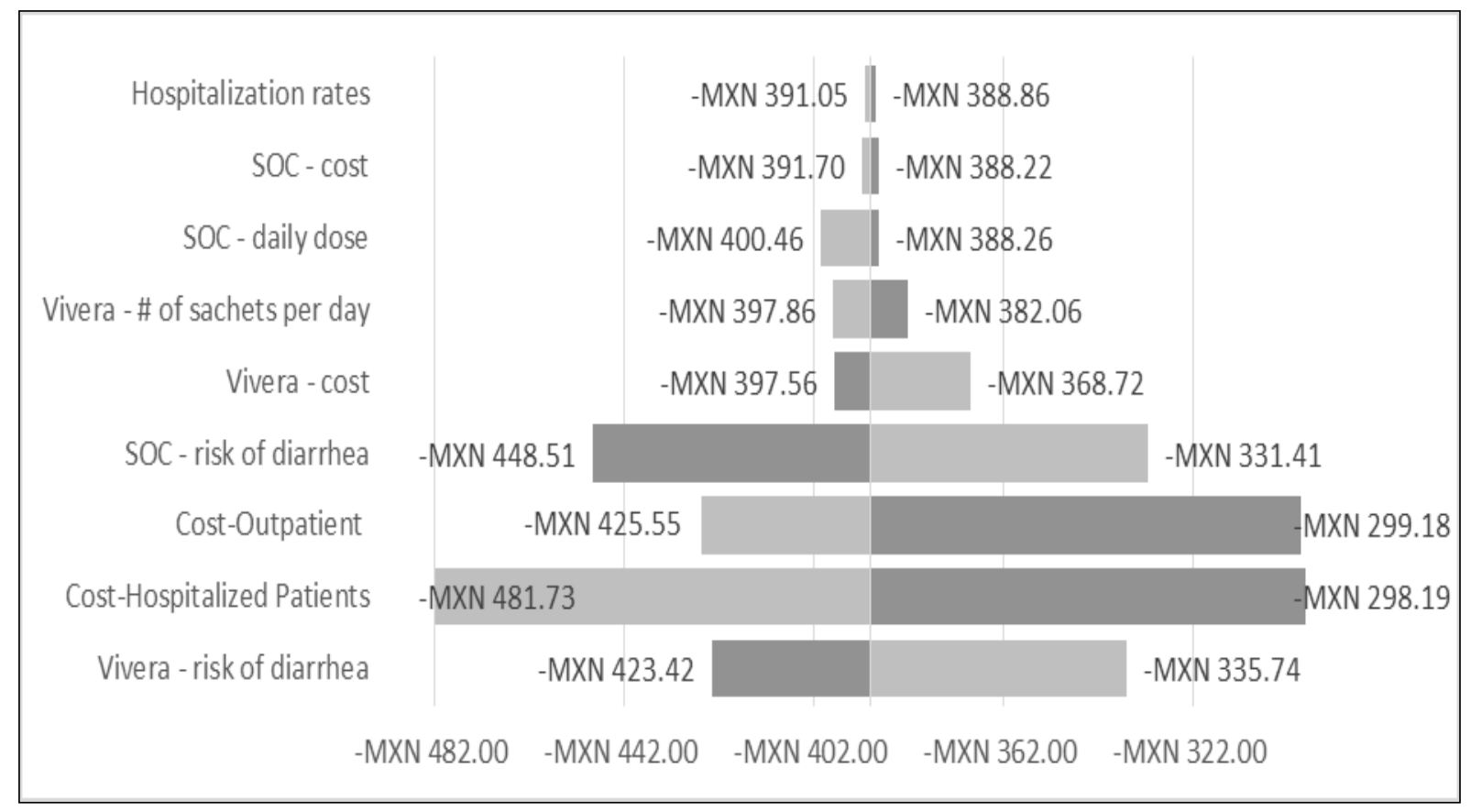

Figure 2: Tornado plot-base case analysis. Parameters contributing the greatest amount of variability to the base case analysis presented in the tornado plot were: costs of outpatient and the numbers of sachets per day of LGG.SOC = Standard of Care.

\section{Discussion}

Using published data on probiotics and costs, this study showed LGG to be cost saving in all scenarios. In base case, the use of LGG would save - MXN 389.96 per children with acute diarrhea and, in the worst case-scenario, it would save - MXN 298.19 per children. The direct medical costs of outpatient and the numbers of sachets per day of LGG were important determinant of cost-effectiveness.

There are few studies evaluating the cost-effectiveness of probiotic use for acute diarrhea - only two cost analyses evaluated probiotics for acute diarrhea was founded. One of them is a cost-benefit analysis regarding the use of two different 
Cost-Effectiveness of Lactobacillus Rhamnosus $G G$ Associated with Oral Rehydration

Therapy Compared with Oral Rehydration Therapy Alone on the Treatment of Children with Acute Diarrhea in Mexico
Copyright: (C)

2020 Hector Daniel Cueto Romero* probiotics (Lactobacillus Acidophilus and Bifidobacterium Bifidum) in the treatment of 106 children hospitalized with acute diarrhea in Thailand. The authors found a median length of hospital stay significantly shorter in the probiotics group than in the controlled group ( 2 vs. 3 days, $\mathrm{p}=0.049$ ) and, taking into consideration parental income loss, a non-significant lower expense was seen in the probiotics group $(6,800.33$ vs. $7,970.92$ Thai Baht, $\mathrm{p}=0.177$ ) [21]. The other study was a cost-benefit analysis of probiotics in ambulatory treatment of acute infectious gastro-enteritis with or without a symbiotic food supplement (containing fructo-oligosaccharides and probiotic strains of Streptococcus Thermophilus, Lactobacillus Rhamnosus, Lactobacillus Acidophilus, Bifidobacterium Lactis and Bifidobacterium Infantis). They found that despite symbiotic supplementation increased cost, add-on medication and extra consultations were reduced, resulting in a reduction of health care cost of $25 \%$ [22]. For other indications some studies have also been describing cost saving in the use of probiotics for the prevention of diarrhea. It was demonstrated the use of the probiotic formula in prophylaxis of Antibioticassociated diarrhea (AAD) and Clostridium difficile-associated diarrhea (CDAD) would lead to estimated savings in direct medical costs [23-27]. Therefore, this study is in line with the others published, reinforcing the proposal of the use of probiotics can save costs reducing costs with the use of probiotics.

To consider the possibility that the cost-savings associated with use of LGG was overestimated, it was modeled different scenarios. Even considering a higher dose or higher costs for treatment, probiotic use dominated (more effective and less costly) no probiotic use. Since gastroenteritis/ acute diarrhea can be expected to produce substantial morbidity, mortality, and health care system costs in Latin America, including Mexico, the results can be substantial to guide management of acute diarrhea management in Mexico [18].

There were some limitations to this model. First, the Szajewska meta-analysis did not report the impact of LGG on the mortality, which was not considered in the model. For this reason, it was assumed that no children would dye in 15 days. Other limitation was about proportion of hospitalized patients. As no data specifically for Mexico was found, only one physician was interviewed to obtain the assumption of $10 \%$ of patients. It is important to emphasize that this doctor considered a private perspective that is different from public perspective in Mexico. Finally, direct medical costs (for in and out-patients) were based in 2003 US dollars of treating rotavirus gastroenteritis in the 2003 birth cohort. These costs were correct using historic inflation rate of Mexico, but it was not considered additional costs like new tests and medicines [28].

\section{Conclusion}

In conclusion, the current model demonstrates that the use of LGG in children from 1 month to 48 months with acute diarrhea in Mexico dominated (more effective and less costly) no probiotic use. Extend the context to a healthcare system perspective, LGG can be cost-savings. Health policy decision makers should consider prioritizing funding oral probiotics among patients with acute diarrhea.

\section{Competing Interests}

Teresa Lemmer is an employee of Kantar - Health Division and Diego Kashiura and Elene Nardi are former employees at Kantar - Health Division, which was hired by Procter \& Gamble Industrial e Comercial LTDA develop the study. Hector Daniel Cuelo Romero is an employee of Procter \& Gamble Industrial e Comercial LTDAand Renata Nahuys Tebyriçá Prioli is a former employee of Procter \& Gamble Industrial e Comercial LTDAwhich funded the study.

\section{Acknowledgements and Funding}

This study was funded by Procter \& Gamble Industrial e Comercial LTDA.

\section{References}

1. Lanata CF, Fischer-Walker CL, Olascoaga AC, Torres CX, Aryee MJ, et al. (2013) Global causes of diarrheal disease mortality in children $<5$ years of age: a systematic review. PLoS One 8: e72788.

2. Boschi-Pinto C, Velebit L, Shibuya K (2008) Estimating child mortality due to diarrhoea in developing countries. Bull World Health Organ 86: 710-717.

3. Bryce J, Boschi-Pinto C, Shibuya K, Black RE; WHO Child Health Epidemiology Reference Group (2005) WHO estimates of the causes of death in children. Lancet 365 : 1147-1152.

4. WHO. Diarrhoeal disease. 2017 [cited 2018 06/06]; Available from: http://www.who.int/news-room/factsheets/detail/diarrhoeal-disease.

5. Ferreira-Guerrero E, Mongua-Rodriguez N, Diaz-Ortega JL, Delgado-Sanchez G, Baez-Saldana R, et al. (2013) Acute diarrheal diseases and feeding practices among children under five years in Mexico. Salud Publica Mex 55 Suppl 2: S314-322.

6. Barr W, Smith A (2014) Acute diarrhea. Am Fam Physician 89: 180-189.

7. Radlovic N, Lekovic Z, Vuletic B, Radlovic V, Simic D, et al. (2015) Acute Diarrhea in Children. SrpArhCelokLek 143: 755-762.

8. Tate JE, Burton AH, Boschi-Pinto C, Steele AD, Duque J, et al. (2012) 2008 estimate of worldwide rotavirusassociated mortality in children younger than 5 years before the introduction of universal rotavirus vaccination 
Cost-Effectiveness of Lactobacillus Rhamnosus GG Associated with Oral Rehydration Therapy Compared with Oral Rehydration Therapy Alone on the Treatment of Children with Acute Diarrhea in Mexico
Copyright: (C)

2020 Hector Daniel Cueto Romero* programmes: a systematic review and meta-analysis. Lancet Infect Dis 12: 136-141.

9. Farthing M, Salam MA, Lindberg G, Dite P, Khalif I, et al. (2013) Acute diarrhea in adults and children: a global perspective. J Clin Gastroenterol 47: 12-20.

10. WHO (2005) The Treatment of diarrhoea : a manual for physicians and other senior health workers. 4th revision World Health Organization:

11. Guarino A, Ashkenazi S, Gendrel D, Lo Vecchio A, Shamir R, et al. (2014) European Society for Pediatric Gastroenterology, Hepatology, and Nutrition/European Society for Pediatric Infectious Diseases evidence-based guidelines for the management of acute gastroenteritis in children in Europe: update 2014. J Pediatr Gastroenterol Nutr 59: 132-152.

12. Allen SJ, Martinez EG, Gregorio GV, Dans LF (2010) Probiotics for treating acute infectious diarrhoea. Cochrane Database Syst Rev Cd003048.

13. Szajewska H, Skórka A, Ruszczyński M, GieruszczakBiałek D (2007) Meta-analysis: Lactobacillus GG for treating acute diarrhoea in children. Alimentary Pharmacology \& Therapeutics 25: 871-881.

14. Ahmadi E, Alizadeh-Navaei R, Rezai MS (2015) Efficacy of probiotic use in acute rotavirus diarrhea in children: A systematic review and meta-analysis. Caspian J Intern Med 6: 187-195.

15. Szajewska H, Skorka A, Ruszczynski M ,GieruszczakBialek D (2007) Meta-analysis: Lactobacillus GG for treating acute diarrhoea in children. Aliment PharmacolTher 25: 871-881.

16. Szajewska H, Skorka A, Ruszczynski M ,GieruszczakBialek D (2013) Meta-analysis: Lactobacillus GG for treating acute gastroenteritis in children--updated analysis of randomised controlled trials. Aliment PharmacolTher 38: 467-476.

17. Fleurence RL, Hollenbeak CS (2007) Rates and probabilities in economic modelling: transformation, translation and appropriate application. Pharmacoeconomics 25: 3-6.

18. Rheingans RD, Constenla $\mathrm{D}$, Antil L, Innis BL, Breuer $T$ (2007) Economic and health burden of rotavirus gastroenteritis for the 2003 birth cohort in eight Latin
American and Caribbean countries. Rev PanamSalud Publica 21: 192-204.

19. Inflation.eu. Historic inflation Mexico - CPI inflation. 2018; Available from: https://www.inflation.eu/inflationrates/mexico/historic-inflation/cpi-inflation-mexico.aspx.

20. XE US Dollar Peso Exchange Rate (USD MXN)Historical Chart. 2018; Available from: https://www.xe.com/currencycharts/?from=USD\&to=MX N.

21. Phavichitr N, Puwdee P, Tantibhaedhyangkul R (2013) Cost-benefit analysis of the probiotic treatment of children hospitalized for acute diarrhea in Bangkok, Thailand. Southeast Asian J Trop Med Public Health 44: 1065-1071.

22. Vandenplas Y, De Hert S, Probiotical study group (2012) Cost/benefit of synbiotics in acute infectious gastroenteritis: spend to save. BenefMicrobes 3: 189-194.

23. KamdeuFansi AA, Guertin JR,LeLorier J (2012) Savings from the use of a probiotic formula in the prophylaxis of antibiotic-associated diarrhea. J MedEcon 15: 53-60.

24. Leal JR, Heitman SJ, Conly JM, Henderson EA, Manns BJ (2016) Cost-Effectiveness Analysis of the Use of Probiotics for the Prevention of Clostridium difficileAssociated Diarrhea in a Provincial Healthcare System. InfectControlHospEpidemiol 37: 1079-1086.

25. Lenoir-Wijnkoop I, Nuijten MJ, Craig J , Butler CC (2014) Nutrition economic evaluation of a probiotic in the prevention of antibiotic-associated diarrhea. Front Pharmacol 5: 13.

26. Vermeersch SJ, Vandenplas $Y$, Tanghe A, Elseviers M , Annemans L (2018) Economic evaluation of S. boulardii CNCM I-745 for prevention of antibiotic associated diarrhoea in hospitalized patients. Acta GastroenterolBelg 81: 269-276.

27. Li N, Zheng B, Cai HF, Chen YH, Qiu MQ, et al. (2018) Cost-effectiveness analysis of oral probiotics for the prevention of Clostridium difficile-associated diarrhoea in children and adolescents. J Hosp Infect 99: 469-474.

28. Infalatino.ue. Historic inflation Mexico - CPI inflation. 2018; Available from: https://www.inflation.eu/inflationrates/mexico/historic-inflation/cpi-inflation-mexico.aspx

Citation: Romero HDC, Prioli RNT, Kashiura D, Nardi E, Lemmer T (2019) Cost-Effectiveness of Lactobacillus Rhamnosus GG Associated With Oral Rehydration Therapy Compared With Oral Rehydration Therapy Alone On the Treatment of Children with Acute Diarrhea in Mexico. Adv Nutri and Food Sci: ANAFS-191. 